\title{
LEVANTAMENTO DO RESÍDUO DE ANTIMICROBIANOS NO LEITE BOVINO COMERCIALIZADO EM HIPERMERCADOS E SUPERMERCADOS NO NORDESTE BRASILEIRO
}

\author{
José Andreey Almeida TELES ${ }^{1}$; Francisco Feliciano da SILVA JÚNIOR ${ }^{2}$; Sandro Márcio \\ Camelo de VASCONCELOS ${ }^{3}$; Rebeka Correia de Souza CUNHA ${ }^{4}$; Gil Dutra FURTADO ${ }^{5}$
}

${ }^{1}$ Graduado em Medicina Veterinária/Universidade Federal de Campina Grande (UFCG); Especialista em Doenças Infecto-contagiosas dos Animais Domésticos/Universidade Federal Rural de Pernambuco (UFRPE); Mestre em Biociência Animal (UFRPE); Doutor em Ciência Veterinária (UFRPE). E-mail: teles.jaa@ gmail.com

${ }^{\mathbf{2}}$ Graduado em Medicina Veterinária/Universidade Federal Rural de Pernambuco (UFRPE); Especialista em Clínica Médica dos Ruminantes/Universidade Estadual Paulista Júlio de Mesquita Filho (UNESP); Mestre em Medicina Veterinária Preventiva e Saúde Pública/Universidade Estadual Paulista Júlio de Mesquita Filho (UNESP); Doutor em Medicina Veterinária Preventiva e Saúde Pública/Universidade Estadual Paulista Júlio de Mesquita Filho (UNESP). E-mail: felicianojr@yahoo.com.br

${ }^{3}$ Graduado em Medicina Veterinária pelo Centro Universitário Cesmac. Consultor em nutrição de pequenos animais. Coordenador de pós-graduação Qualittas. E-mail: smcamelo@hotmail.com

${ }^{4}$ Graduada em Nutrição pela Faculdade Maurício de Nassau. Preceptora de estágio curricular supervisionado na atenção básica. E-mail: rebekacorreia0@gmail.com

${ }^{5}$ Graduando em Medicina Veterinária / Faculdade Maurício de Nassau (UNINASSAU / PB); Engenheiro Agrônomo / Universidade Federal da Paraíba (UFPB); Doutor em Psicobiologia / Universidade Federal do Rio Grande do Norte (UFRN); Agrônomo-Sócio da Cooperativa de Agronegócio (COOPAGRO). E-mail: gdfurtado@hotmail.com

Resumo. O leite é um alimento riquíssimo em nutrientes, sendo que o mesmo também pode gerar alguns malefícios quando manipulado ou produzido sem os devidos cuidados e fiscalização. A inocuidade deste alimento frente a resíduos químicos, a exemplo dos antimicrobianos é primordial para a saúde, diante do exposto visando avaliar a qualidade do leite e composto lácteo comercializado em hipermercados e supermercados de Maceió, estado de Alagoas, Nordeste do Brasil, foram analisados 42 espécimes, com o objetivo de detectar resíduos de antimicrobianos. Todas as amostras foram submetidas ao Teste Copan (CH-ATK), onde os métodos de diagnóstico seguiram as recomendações do fabricante. $\mathrm{O}$ tamanho amostral foi calculado considerando um limite de confiança de $95 \%$ e um erro de estimativa de prevalência de $5 \%$ e proporção esperada de $50 \%$. A metodologia baseou-se em pesquisa e na obtenção de dados no acervo da biblioteca setorial do Centro Universitário CESMAC em Marechal Deodoro, além de artigos, periódicos e dissertações adquiridas via internet. Em nenhuma das amostras testadas foi detectado resíduo de antimicrobianos, ficando assim dentro do preconizado pela legislação vigente. 
Palavras-chave: Antibióticos; Saúde Pública; CH-ATK.

\section{ANTIMICROBIAL WASTE POSING IN CATTLE MILK MARKETED IN HIPERMERCADOS AND SUPERMARKETS IN NORTHEAST BRAZIL}

Abstract. Milk is a food rich in nutrients, and it can also generate some harmful effects when handled or produced without the proper care and supervision. The safety of this food in front of chemical waste, the example of antimicrobials is essential for health, against the fore going, to evaluate the quality of milk and dairy compound sold in hypermarkets and supermarkets in Maceió, state of Alagoas, Northeast Brazil, 42 samples were analyzed, with the objective of detect antimicrobial residues. All samples were subjected to Copan test (CH ATK), where the diagnostic methods followed the manufacturer's recommendations. The sample size was calculated considering a $95 \%$ confidence level and a prevalence estimate of error of $5 \%$ and expected rate of $50 \%$. The methodology was based on research and data collection at the sectoral library collection of the University Center CESMAC in Marechal Deodoro, in addition to articles, journals and dissertations acquired by the Internet. In none of the samples tested was detected antimicrobial residue, thus within the envisaged by law.

Keywords: Antibiotics; Public health; CH-ATK.

\section{RESIDUOS ANTIMICROBIANOS QUE SE PRESENTAN EN LA LECHE DEL GANADO COMERCIALIZADO EN HIPERMERCADOS Y SUPERMERCADOS EN NORDESTE DE BRASIL}

Resumen. La leche es un alimento rico en nutrientes, y también puede generar algunos efectos dañinos cuando se manipula o produce sin el cuidado y la supervisión adecuados. La inocuidad de este alimento frente a los desechos químicos, el ejemplo de los antimicrobianos es esencial para la salud, en primer lugar, para evaluar la calidad de la leche y los compuestos lácteos vendidos en hipermercados y supermercados en Maceió, estado de Alagoas, Nordeste de Brasil, se analizaron 42 muestras, con El objetivo de detectar residuos antimicrobianos. Todas las muestras se sometieron a la prueba de Copan (CH ATK), donde los métodos de diagnóstico siguieron las recomendaciones del fabricante. El tamaño de la muestra se calculó considerando un nivel de confianza del 95\% y una estimación de la prevalencia del error del 5\% y la tasa esperada del 50\%. La metodología se basó en la investigación y la recopilación de datos en la colección de bibliotecas sectoriales del Centro Universitario CESMAC en Marechal Deodoro, además de artículos, revistas y disertaciones adquiridas por Internet. En ninguna de las muestras analizadas se detectó residuo antimicrobiano, por lo tanto dentro de lo previsto por la ley.

Palabras clave: Antibióticos; Salud pública; CH-ATK. 


\section{INTRODUÇÃO}

A vital necessidade de se ter alimentos saudáveis, com alto valor nutricional, disponíveis e acessíveis à população, deve-se a grande importância da ciência e da tecnologia de alimentos na melhoria da qualidade de vida do ser humano. Desde o nascimento do ser humano, o leite apresenta-se quase indispensável de sua alimentação (SILVA, 1997). É considerado um alimento completo em nutrientes facilmente assimiláveis (ZENI et al., 2013).

Para suprir a necessidade de proteínas, vitaminas, enzimas, gordura, lactose, glicerídeos e sais, o leite bovino vem fazendo parte da base alimentar nos primeiros anos de vida e se caracteriza por ser um dos principais produtos agropecuários brasileiros, entretanto, são necessárias melhorias da qualidade nos processos para que problemas em nível de segurança alimentar sejam evitados (SILVEIRA; CARVALHO; TEIXEIRA, 1998; SOUSA et al., 2011).

Agentes químicos são encontrados mundialmente contaminando o leite bovino e seus derivados, sendo os resíduos de antimicrobianos os mais frequentes (NERO et al., 2007). Tais resíduos no leite deve-se à utilização indiscriminada de medicamentos na prática veterinária, além do não cumprimento do período de carência dessas substâncias (PONTES NETTO et al., 2005), tendo base ainda na má higienização de equipamentos e utensílios da ordenha e da indústria ou pela adição fraudulenta, onde é possível adicionar água para aumentar o volume, além de diversas outras substâncias para mascarar a adição da água (MENDES et al., 2010).

Ainda numa perspectiva fraudulenta, também é possível adicionar substâncias conservantes que mascaram a acidez, minimizando a deficiência da qualidade higiênica do leite. A única substância que é possível retirar do leite é a gordura. Portanto, o desnate, quando feito ainda na propriedade rural, também é considerado fraude (BORGES et al., 2000).

Em decorrência do seu processo produtivo ou ainda vinculado ao seu processamento, os alimentos podem conter alguns resíduos, todavia, estes não podem comprometer a integridade orgânica dos seres humanos e animais (BRASIL, 1999).

Dessa forma é que, no Brasil, existe o Programa Nacional de Controle de Resíduos e Contaminantes (PNCRC-MAPA) responsável pelo controle oficial da segurança do leite em relação à presença de resíduos (medicamentos veterinários e contaminantes inorgânicos), além de avaliar os demais produtos decorrentes da cadeia agroalimentar. O Limite Máximo de Resíduos (LMRs) caracterizado pela quantidade máxima de determinada substância que um alimento pode conter, pode ser utilizado como medida de detecção de não conformidades para a tomada de ações regulatórias (CODEX ALIMENTARIUS, 2009). 
O Ministério da Agricultura, Pecuária e Abastecimento autoriza o uso de cerca de 15 compostos antimicrobianos como aditivos na alimentação animal e outros 50 para fins terapêuticos, muitos dos quais de uso comum entre as diversas espécies animais, como bovinos, suínos, aves, cães, caprinos, etc (PALERMO-NETO; ALMEIDA, 2006).

Dentre os antibióticos mais comumente utilizados em animais produtores de alimentos, em particular para bovinos destinados a produção de leite, destacam-se os betalactâmicos (penicilinas e cefalosporinas); tetraciclinas (oxitetraciclinas, tetraciclinas e clortetraciclinas); aminoglicosídeos (estreptomicina, neomicina e gentamicina); macrolídeos (eritromicina) e sulfonamidas (sulfametazina), sendo os betalactâmicos responsáveis por cerca de 95\% dos resíduos encontrados no leite bovino. Estes têm sua presença no leite principalmente em consequência da administração por infusão intramamária para tratamento das mastites e ainda, por adições com propósitos fraudulentos (OLIVEIRA, 2008).

Os riscos à saúde humana devido à presença de resíduos de antibióticos no leite estão relacionados principalmente com o desencadeamento de fenômenos alérgicos em indivíduos sensíveis, com os efeitos tóxicos e carcinogênicos, com alterações no equilíbrio da flora intestinal e com a seleção de bactérias resistentes no trato digestivo dos consumidores (CACCIATORE et al., 2004).

O impacto da ingestão de alimentos com resíduos de antibióticos na saúde pública ainda não está completamente elucidado, entretanto, há evidências suficientes para que cause apreensão. É inegável o fato de que a exposição contínua a agentes antimicrobianos é responsável pelo surgimento de resistência bacteriana, dependendo do período e frequência de exposição, assim como os níveis de concentração, tendo em vista que os antibióticos são utilizados extensamente na pecuária (GOBBO, 2006).

Inicialmente, os antibióticos eram aplicados apenas com propósito terapêutico, entretanto, com o advento de novos conhecimentos e a descoberta de outros compostos antimicrobianos, estes passaram a ser empregados como preventivos de doenças e como promotores de crescimento (GOBBO, 2006).

Tendo em vista a importância em saúde pública, bem como a carência de informações dessa natureza no estado de Alagoas, objetivou-se determinar a prevalência de resíduos antimicrobianos no leite e composto lácteo bovinos vendidos em hipermercados e supermercados de Maceió. 


\section{MATERIAL E MÉTODOS}

Foram avaliadas, em dualidade, 42 amostras de leite bovino, de marcas distintas e disponíveis no comércio local, sendo 38 (90,48 \%) tipo UHT e leite pasteurizado e 04 de composto lácteo integral (9,52\%), obtidos em 03 hipermercados e supermercados, no município de Maceió, comercializados no período de julho a novembro de 2016, submetidas ao Teste Copan $(\mathrm{CH}$ ATK) - Teste Único P\&S 100, visando levantamento epidemiológico de resíduos de betalactâmicos, tetraciclinas, sulfonamidas, aminoglicosídeos e macrolídeos. Das 42 amostras, 19 eram tipo UHT, 19 pasteurizadas e 04 eram compostos lácteos integrais.

O material foi adquirido, acondicionado e transportado para o laboratório de doenças infectocontagiosas dos animais domésticos do Curso de Medicina Veterinária do Cesmac, conforme faria um cliente ao transportar compras para sua residência. Os métodos de diagnóstico utilizados seguiram as recomendações do fabricante do kit.

O tamanho amostral foi calculado considerando um limite de confiança de $95 \%$ e um erro de estimativa de prevalência de $5 \%$ e proporção esperada de $50 \%$, pois não existiam estudos de base que refiram-se à prevalência do índice de antimicrobiano no leite bovino no Estado, sendo acrescido de $20 \%$, para que eventuais perdas não comprometam a representatividade da amostra (ZAR, 1996).

Para processamento, foram adicionados $100 \mu \mathrm{l}$ da amostra a ser testada em microtubos contendo o reagente associado a um indicador. Posteriormente, os microtubos foram incubados em banho-maria a $64,5^{\circ} \mathrm{C}$, durante 03 horas. Após isso, interpretaram-se os resultados, onde tubos que apresentaram cor amarelada eram considerados negativos e tubos com coloração roxa, eram reagentes positivos.

O controle de integridade e viabilidade técnica do kit utilizado foi feito a partir da observação do selo indicador aplicado na parte inferior da tampa da caixa do referido teste. Este selo possui uma janela de indicação que muda de cor quando o produto é exposto a altas temperaturas. $\mathrm{O}$ indicador deve permanecer na cor branca se enviado e armazenado corretamente (Figura 1a e b). Caso o produto tenha sido exposto a uma temperatura de $40,6^{\circ} \mathrm{C}$ ou mais, o indicador da janela irá adquirir a coloração preta, mostrando que o mesmo está tecnicamente inviável para uso.

\section{RESULTADOS E DISCUSSÃO}

As 42 amostras de leite tipo UHT e pasteurizado e composto lácteo integral industrializados, utilizadas para o teste, foram negativas para a detecção de resíduo de antimicrobiano (Tab. 1). 
Tabela 1. Resultado das amostras de leite e composto lácteo industrializados, avaliados pelo teste Copan (CH ATK) - Teste Único P\&S 100 de acordo com a marca e tipo, comercializadas de julho a novembro de 2016 em Maceió, estado de Alagoas, Nordeste do Brasil.

\begin{tabular}{|c|c|c|c|c|c|c|c|c|c|c|c|c|c|c|}
\hline \multirow[b]{3}{*}{ MARCAS } & \multicolumn{14}{|c|}{ CLASSIFICAÇÃO DOS LEITES } \\
\hline & \multicolumn{7}{|l|}{ UHT } & \multicolumn{2}{|c|}{ INTEGRAL } & \multicolumn{5}{|c|}{ OUTROS } \\
\hline & 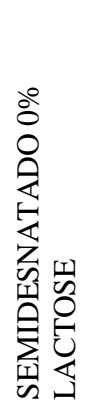 & 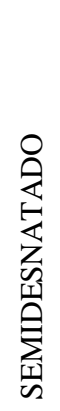 & 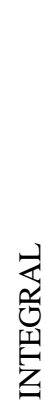 & 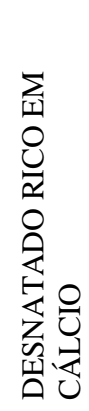 & 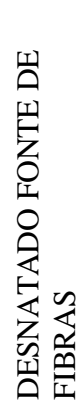 & 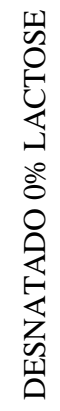 & 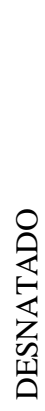 & 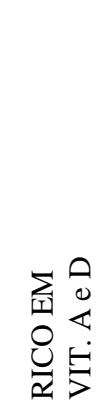 & 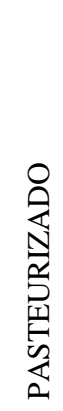 & 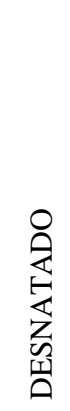 & $\begin{array}{l}0 \\
1 \\
0 \\
0 \\
\vdots \\
0 \\
\vdots \\
0 \\
0 \\
0 \\
0 \\
0\end{array}$ & 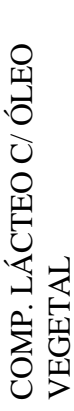 & 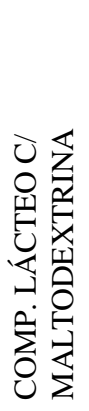 & 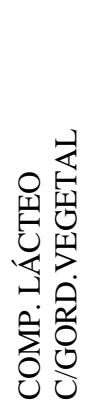 \\
\hline A & & $\mathrm{N}$ & $\mathrm{N}$ & & & & & & & & & & & $\mathrm{N}$ \\
\hline $\mathrm{B}$ & & & & & & & $\mathrm{N}$ & & & & & & & \\
\hline $\mathrm{C}$ & & & & & & & & & & & $\mathrm{N}$ & & & \\
\hline $\mathrm{D}$ & & & & & & & $\mathrm{N}$ & & & & & & & \\
\hline $\mathrm{E}$ & & & $\mathrm{N}$ & & & & & & $\mathrm{N}$ & & & & & \\
\hline $\mathrm{F}$ & & & $\mathrm{N}$ & & & & & & & & & & & \\
\hline G & & & & & & & & & $\mathrm{N}$ & & & & & \\
\hline $\mathrm{H}$ & & & & & & & & & $\mathrm{N}^{*}$ & & & & & \\
\hline I & & $\mathrm{N}$ & & & & & & $\mathrm{N}$ & $\mathrm{N}$ & $\mathrm{N}^{*}$ & & & & \\
\hline $\mathrm{J}$ & & & & & & & & & $\mathrm{N}$ & & & & & \\
\hline $\mathrm{K}$ & & & $\mathrm{N}$ & & & & & & & $\mathrm{N}$ & & & & \\
\hline $\mathrm{L}$ & & & $\mathrm{N}$ & & & & & & & & & & & \\
\hline $\mathrm{M}$ & & & & & & & & & $\mathrm{N}$ & & & & $\mathrm{N}$ & \\
\hline $\mathrm{N}$ & & & & & & $\mathrm{N}$ & $\mathrm{N}$ & & & & & & & \\
\hline $\mathrm{O}$ & & & $\mathrm{N}$ & & & & & & $\mathrm{N}^{*}$ & & & $\mathrm{~N}$ & & \\
\hline $\mathrm{P}$ & $\mathrm{N}$ & & $\mathrm{N}$ & $\mathrm{N}$ & $\mathrm{N}$ & & & & $\mathrm{N}$ & $\mathrm{N}$ & & & & \\
\hline Q & & & & & & & & & $\mathrm{N}$ & & & & & \\
\hline $\mathrm{R}$ & & $\mathrm{N}$ & & & & & $\mathrm{N}$ & & & & & & & \\
\hline $\mathrm{S}$ & & & $\mathrm{N}$ & & & & & & & & & & & \\
\hline $\mathrm{T}$ & & & & & & & & & $\mathrm{N}$ & $\mathrm{N}$ & & & & \\
\hline $\mathrm{U}$ & & $\mathrm{N}$ & & & & & & & & & & & & \\
\hline
\end{tabular}

$\mathrm{P}=$ positivo / $\mathrm{N}$ = negativo / $\mathrm{N}^{*}$ Amostras testadas em dois momentos distintos em função do lote. 
Do total de 42 amostras, 04 (9,52\%) contemplaram a avaliação de resíduo antimicrobiano em composto lácteo e $38(90,48 \%)$ eram representadas por leite tipo UHT e pasteurizado, visando quantificar resíduo nestes tipos de alimento.

Dos 38 espécimes de leite, 21 eram representados pelo produto integral, 12 eram de leite desnatado e 05 unidades eram do leite semidesnatado. Duas amostras de leite tiveram os testes repetidos em função do lote, pois na mesma coleta, o produto em prateleira apresentava números de partida distintos.

De acordo com os resultados obtidos, a ausência total de resíduos nas amostras avaliadas se iguala aos resultados obtidos por Lopes et al. (1998), citados por Borges et al. (2000), que observaram uma prevalência de 0\%, em amostras de leite pasteurizado tipo C provenientes de duas marcas comerciais, na cidade de Campinas (SP).

Portz, Couto e Ferreira (2014) ao avaliarem 30 amostras de leite oriundas de produtores rurais e do comércio, do Distrito Federal, observaram que todas apresentaram resultados negativos para resíduos de antibióticos.

Souza (2006), ao realizar pesquisa de resíduos de antimicrobianos em 12 espécimes de leite, no município de Sacramento-MG, no ano de 2006, encontrou 100\% de negatividade.

Nessa perspectiva, caso o uso de antibióticos ocorra somente no período em que as vacas não estejam produzindo leite e for obedecido o período de carência, informado pelo laboratório fabricante, os níveis de antibiótico circulantes serão nulos ou muito baixos, sofrendo significativa redução, o que resultará em risco mínimo de passagem destes resíduos para o leite (BRASIL, 2007).

Macedo e Freitas (2009) tiveram 0\% de prevalência como resultado frente à investigação de resíduos no leite produzido e comercializado no Distrito Federal, sendo 10 amostras de leite cru e 20 beneficiados (Tipo C). Diferentemente desta pesquisa e dos resultados apresentados pelos autores mencionados anteriormente, no que se refere à presença em quantidade detectável pelo limite do kit utilizado, Folly e Machado (2001) obtiveram 4,33\% das amostras positivas de um total de 300 amostras testadas para $\beta$-lactâmicos e tetraciclinas em espécimes de leite tipo C e Integral (Fazenda do comércio da Região Norte do Estado do Rio de Janeiro), ao quê, estes associam o uso exacerbado de antibióticos no sistema produtivo leiteiro da região.

Ultrapassando estes resultados, Morais et al. (2010) detectou 15 (19\%) espécimes positivos para resíduos de antimicrobianos a partir da análise de 79 amostras de leite pasteurizado do tipo B de diferentes fabricantes, adquiridos em estabelecimentos comerciais 
do Estado do Paraná, Brasil, os autores ressaltam a importância da fiscalização, para justificar tais resultados.

Para uma representatividade ainda maior, Ferreira et al. (2010), detectou em 922 amostras de leite cru, pasteurizado (integral) e UHT (integral, desnatado e semidesnatado), onde $84(8,47 \%)$ se mostraram positivas para a presença de resíduos antimicrobianos, sendo $53(5,34 \%)$ de leite cru, $19(1,92 \%)$ de leite pasteurizado e $12(1,21 \%)$ de UHT, produzidos no Estado de Goiás, sob fiscalização do SIF (Serviço de Inspeção Federal), entre abril e novembro de 2010, o autor justifica a prevalência de resultados positivos a não realização das análises de antibióticos e a carente fiscalização nas plataformas de recepção das indústrias de laticínio.

Contrariamente ao que foi encontrado nos trabalhos onde houve percentuais significativos de prevalência, a pesquisa em questão, sugere que existe um melhor controle no uso de antimicrobianos nos sistemas produtivos que fornecem leite aos produtos que foram avaliados. Pode ainda, a negatividade dos resultados, estar associada à menor quantidade detectável pelo kit, não sendo necessariamente negativos, mas sim detentores de pequenas quantidades.

\section{CONCLUSÃO}

Diante do exposto, é possível afirmar que não existe resíduo de antimicrobiano (betalactâmicos, tetraciclinas, sulfonamidas, aminoglicosídeos e macrolídeos) nos leites e compostos lácteos avaliados.

\section{REFERÊNCIAS}

BORGES, G.T.; SANTANA, A.P.; MESQUITA, A.J.; MESQUITA, S.Q.P.; SILVA, L.A.F.; NUNES, V.Q. Ocorrência de resíduos de antibióticos em leite pasteurizado integral e padronizado produzido e comercializado no estado de goiás. Ciência Animal Brasileira. Goiás, v. 1, n. 1, p. 59-63, 2000.

BRASIL, Instrução Normativa no 42 de 20 de dezembro de 1999 - Ministério da Agricultura, Pecuária e Abastecimento. Referente a alteração do Plano Nacional do Controle de Resíduos em Produtos de Origem Animal - PNRC e os Programas de Controle de Resíduos em Carne PCRC, Mel - PCRM, Leite - PCRL e Pescado PCRP. Diário Oficial da República Federativa do Brasil: seção 1, p. 253-267. Brasília 22 de dezembro de 1999. 
BRASIL. Universidade de Brasília, UNB. Análises microbiológicas para leite fluido. Brasília, DF. Universidade de Brasília, 2007. Disponível em: http://www.respostatecnica.org. br/dossie-tecnico/downloadsDT/MTk3. Acesso em: 02 de maio de 2019.

CACCIATORE, G.; PETZ, M.; RACHID, S.; HAKENBECK, R.; BERGWERFF, A.A. Development of an optical biosensor assay for detection of b-lactan antibiotics in milk using the penicillin-binding protein 2X. Analytica Chimica Acta, v. 520, p. 105-115, 2004.

CODEX ALIMENTARIUS. Guidelines for design and implementation of national regulatory food safety assurance programme associated with the use of veterinary drugs in food producing animals. CAC/GL. 2009. Disponível em: http://www.codexalimentarius.org/standards/. Acesso em: 06 mai 2019.

FERREIRA, P. P.; NICOLAU, E. S.; SANTOS, T.; SOARES, N. R. Qualidade do Leite Produzido no Estado de Goiás: Ocorrência de Resíduos de Antimicrobianos. Trabalho de Iniciação Científica. Programa Institucional de Bolsa de Iniciação Científica - PIBIC. Escola de Veterinária e Zootecnia, Goiás, p. 16, 2010.

FOLLY, M.M.; MACHADO, S.C.A. Determinação de resíduos de antibióticos, utilizando-se métodos de inibição microbiana, enzimático e imunoensaios no leite pasteurizado comercializado na região norte do estado do Rio de janeiro, Brasil. Ciência Rural, Santa Maria, v. 31, n. 1, p. 95-98, 2001.

GOBBO, S.P. Padronização e desenvolvimento de reagentes imunoenzimáticos para pesquisa de ciprofloxacina em produtos de origem animal [tese]. Piracicaba: Universidade de São Paulo. p. 103. 2006.

MACEDO, L.C.S.; FREITAS, J.A. Ocorrência de Resíduos de Antimicrobianos em leite. Revista Ciência Agrária, n. 52, p. 147-157, 2009.

MENDES, C.G.; SAKAMOTO, S.M.; SILVA, J.B.A.; JÁCOME, C.G.M.; LEITE, A.I. Análises físico-químicas e pesquisa de fraude no leite informal comercializado no município de Mossoró, RN. Ciência Animal Brasileira, v. 11, n. 2, p. 349-356, 2010. 
MORAIS, C. M. Q. J.; DURAES, T. S.; NÓBREGA, A. W.; JACOB, S. C. Presença de resíduos de antibióticos em leite bovino pasteurizado. Food Science and Technology, v. 30, supl. 1, p. 20-24, 2010.

NERO, L. A.; MATTOS, M. R.; BELOTI, V.; BARROS, M. A. F.; FRANCO, B. D. G. M. Resíduos de antibióticos em leite cru de quatro regiões leiteiras no Brasil. Ciência e Tecnologia de Alimentos, Campinas, v. 27, n. 2, p. 391-393, 2007.

OLIVEIRA, N.J. Antibióticos promotores de crescimento na produção animal. In: $4^{\circ}$ Encontro de zootecnista do norte de minas: novas perspectivas mercadológicas, 2008, Montes Claros. Anais. Montes Claros: Núcleo de Ciências Agrárias da UFMG, 2008. p. 89-115.

PALERMO-NETO, J.; ALMEIDA, R.T. Antimicrobianos como aditivos em animais de produção. In: SPINOZA, H.S.; ÓRNIAK, S.L.; BERNARDI, M.M., eds. Farmacologia aplicada à medicina veterinária. Rio de Janeiro: Guanabara Koogan, 2006. p. 641-658.

PONTES NETTO, D.; LOPES, M. O.; OLIVEIRA, M. C. S.; NUNES, M. P.; MACHINSKI JUNIOR, M.; BOSQUIROLI, S. L.; BENATTO, A.; BENINI, BOMBARDELLI, A. L. C.; VEDOVEllo FILHO, D.; MACHADO, E.; BELMONTE, I. L.; ALBERTON, M.; PEDROSO, P. P.; SCUCATO, E. S. Levantamento dos principais fármacos utilizados no rebanho leiteiro do Estado do Paraná. Acta Scientiarum, Animal Sciences, Maringá, v. 27, n. 1, p. 145-151, 2005.

PORTZ, A.J.; COUTO, E.P.; FERREIRA, M.A. Resíduos de antibióticos e qualidade microbiológica de leite cru e beneficiado. Revista do Instituto Adolfo Lutz, v. 73, n. 4, p. 345-50, 2014.

SILVA, P.H.F. Leite: Aspectos de Composição e Propriedades. Química Nova na Escola, n. 6, p. 3-5, novembro, 1997.

SILVEIRA, I.A.; CARVALHO, E.P.; TEIXEIRA, D. Influência de microganismos psicrotróficos sobre a qualidade do leite refrigerado: uma revisão. Higiene Alimentar, v. 12, n. 55, p. $21-27,1998$. 
SOUSA, F.C.; CRUZ, C.S.A.; SILVA, L.M.M.; FEITOSA, M.K.S.B.; SILVA J.N. Qualidade físico-química de leites pasteurizados tipo $\mathrm{C}$ comercializados na região do Cariri cearense. Revista Verde, Mossoró, RN. v. 6, n. 3, p. 258-262, 2011.

SOUZA, V. Características físico-químicas, microbiológicas, celulares e detecção de resíduos de antibióticos em amostras de leite de tanque comunitário. Dissertação (Dissertação em Ciências agrárias e Veterinárias) - Unesp, Campus de Jaboticabal, São Paulo. 2006.

ZAR, J.H. Bioestatistical analysis. New Jersey: Prentice-Hall, 1996. 718 p.

ZENI, M.P.; MARAN, M.H.S.; SILVA, G.P.R.; CARLI, E.M.; PALEZI, S.C. Influência dos microrganismos psicrotróficos sobre a qualidade do leite refrigerado para produção de UHT. Unoesc \& Ciência - ACET, Joaçaba, v. 4, n. 1, p. 61-70, 2013. 